Trabajos originales.

\title{
APORTES A LA EPIDEMIOLOGIA DE LA DIFTERIA
}

\author{
For los Dies. HERNAN ROMERO, J. M. BORGOÑO. M. CERVANTES, E. DUSSERT, \\ R. HUERTA. N. KLIWADENKO y J, VILDOSOLA. \\ Sarvicio Nacional de Salubridad : Instituto Bacteriolópico.
}

\section{Introducción.}

En el otoño pasado culminó la preocupación por el número elevado de casos de difteria en la comuna de Quilpué, algunos de los cuales habían aparecido en niños recientemente vacunados. En el último trimestre de 1951, el Jefe Provincial de Valparaíso había inyectado, con la ayuda de la Cruz Roja 1ocal, vacuna mixta contra la difteria y la tos convulsiva en sujetos de 3 meses a 6 años de edad, según la práctica habitual y toxoide en los de 7 a 14 años. Creyó haber cubierto $16 \%$ del primer grupo y $74 \%$ del segundo. Sus cálculos de población aparecen un tanto abultados, en comparación con los que tiene el Servicio Nacional de Salubridad. Según éstos, los porcentajes habrian sido de 21.8 y 85.8 , respectivamente. Sorprendió al doctor Ricardo Montero que la incidencia no decayera.

Por cuanto la situación era en sí misma alarmante y precipitada, además, por la necesidad de estimar la protección que estaban confiriendo esos agentes inmunizantes, intervino el Departamento de Epidemiologia y Sanidad Internacional para colaborar en los esfuerzos. Para fundamentar su acción y hacerla más efectiva, creyó conveniente recoger antes y simultáneamente algunos indicios que le permitieron orientarse sobre el estado actual de la epidemiología de nuestra difteria y procedió así a:
1) Acumular y analizar los datos sobre la evolución de la enfermedad que existen en el Departamento de Bioestadística de la Dirección General de Sanidad;

2) Estudiar los resultados alcanzados hasta el momento con la vacunación mixta realizada en Santiago; además, poner al día la información sobre la materia presentada a las Segundas Jornadas de Salubridad por el doctor Conrado Ristori y uno de nosotros (J. V.).

3) Practicar Schick en individuos de distintas edades, a quienes se suponen susceptibles, como asimismo en algunos recientemente vacunados. Se tomaron también algunas muestras de sanğre en ambos grupos, a fin de que el doctor Otto Hoffman, del Instituto Bacteriológico, determinara la concentración de antitoxina circulante;

4) Compulsar los resultados de los estudios bacteriológicos que están realizando el Departamento de Laboratorios y Control de ese mismo Instituto y la Cátedra de Mierobiología de la Escuela de Salubridad;

5) Mientras tanto, el Departamento de Epidemiología convino con la Jefatura de Valparaíso en ejecutar un plan que consistió en recorrer casa por casa las poblaciones de Quilpué, Retiro, Paso Hondo y El Belloto, con objeto de: a) inyectar toxolde diftérico en niños de 3 meses a 10 años de edad que no hubieran sido inmunizados; b) una segunda 


\begin{tabular}{|c|c|c|c|c|c|}
\hline \multicolumn{6}{|c|}{$\begin{array}{l}\text { REPUBLICA DE CHILE } \\
\text { DIFTERIA } \\
1917-1951\end{array}$} \\
\hline \multicolumn{3}{|c|}{ CIFRAS } & \multicolumn{3}{|c|}{ TASAS } \\
\hline Años & Casos & Defunciones & Morbilidad & Mortalidad & Letalidad \\
\hline 1917 & & 252 & & 6.9 & \\
\hline 1918 & & 236 & & 6.4 & \\
\hline 1919 & & 217 & & 5.8 & \\
\hline 1920 & & 232 & & 0.1 & \\
\hline $1 \subseteq 21$ & & 176 & & 4.6 & \\
\hline 1922 & & 137 & & 3.5 & \\
\hline 1923 & & 159 & & 4.0 & \\
\hline 1824 & & 114 & & 2.9 & \\
\hline 1825 & & 77 & & 1.9 & \\
\hline 1926 & & 98 & & 2.4 & \\
\hline 1927 & & 126 & & 3.0 & \\
\hline 1928 & & 99 & & 2.3 & \\
\hline 1929 & & 207 & & 4,8 & \\
\hline 1930 & & 224 & & 5.1 & \\
\hline 1931 & & 207 & & 4.6 & \\
\hline 1932 & 624 & 184 & 13.7 & 4.0 & 29.5 \\
\hline 1933 & 645 & 234 & 13.9 & 5.0 & 36.3 \\
\hline 1934 & 774 & 298 & 16.5 & 6.3 & 38.5 \\
\hline 1935 & 600 & 201 & 12.6 & 4.2 & 33.5 \\
\hline 1936 & 560 & 183 & 11.8 & 3.8 & 32.2 \\
\hline 1937 & 547 & 139 & 1.1 .2 & 2.8 & 25.4 \\
\hline 1938 & 600 & 141 & 12.1 & 2.8 & 23.5 \\
\hline 1939 & 661 & 145 & 13.2 & 2.9 & 21.9 \\
\hline 1940 & 458 & 100 & 9.0 & 2.0 & 21.8 \\
\hline 1941 & 543 & 132 & 10.5 & 2.5 & 24.3 \\
\hline 1942 & 743 & 183 & 14.2 & 3.5 & 24.6 \\
\hline 1843 & 1,088 & 209 & 20.4 & 3.9 & 192 \\
\hline 1944 & 1,162 & 191 & 21.5 & 3.5 & 16.4 \\
\hline 1945 & 1,235 & 201 & 22.4 & 3.6 & 16.3 \\
\hline 1946 & 912 & 150 & 16.3 & 2.7 & 16.4 \\
\hline 1847 & 948 & 180 & 16.5 & 3.2 & 19.1 \\
\hline 1948 & 931 & 221 & 16.0 & 3.8 & 23.7 \\
\hline 1849 & 8.58 & 218 & 14.4 & 3.7 & 25.4 \\
\hline 1950 & 1,023 & 186 & 16.9 & 3.1 & 18.2 \\
\hline 1951 & 1,449 & 160 & 23.4 & 2.6 & 11.0 \\
\hline
\end{tabular}


dosis de ese mismo toxoide a los que habían recibido una sola de cualquiera de los 2 antigenos; c) una tercera en quienes habían completado las 2 dosis, hacía un año o más; d) practicar Schick en escolares que hubieran sido vacunados con 2 dosis, 3 meses antes, por lo menos y también en personas que no hubieran recibido ningún antígeno; e) tomar muestras faríngeas para la búsqueda de portadores y de sangre para determinación de antitoxinas en vacunados; f) asegurar la hospitalización de los enfermos y el tratamiento inmediato con suero antidiftérico y penicilina gratuitos de quienes debían esperar algunas horas antes de ingresar a un establecimiento; g) vigilar los focos, o sea, la casa de los pacientes al menos día por medio y hasta el sexto día para la cuarentena de los contactos. Siguiendo política general $\mathrm{y}$, a nuestro juicio, bien fundada del Departamento, no recurrimos en ellos a inmunización pasiva con suero. En la tarea cooperaron nuestros médicos y enfermeras con el personal de la Jefatura de Valparaiso, las enfermeras de la Unidad Sanitaria Cerro Barón e instructoras y alumnas de la Escuela de Enfermería Carlos Van Buren.

\section{1.-Evolución de la difteria.}

Como en casi todo el mundo, se ha observado su disminución progresiva en los últimos años; así, la mortalidad, que era en 1917-1920, de 7 por 100,000, ha descendido a 2 (Tabla $\mathrm{N}^{\circ}$ 1). La morbilidad ha tenido fluctuaciones que, con esa excepción, deben haberse debido más bien a irregularidades en la denuncia. $\mathrm{Si}$ se estudian sus curvas (Gráfico $\mathbf{N}^{9} \mathrm{l}$ ), se advierte descenso en el norte, que deja entrever la posibilidad de que esté terminando un ciclo y aumento en el sur, como si estuviera comenzando uno nuevo. Esta circunstancia y las informaciones de Quilpué que exhibiremos (escasez de portadores, características peculiares de los cultivos faringeos, aparente ausencia de inmunidad base), inducen a sospechar que el problema pue- da ofrecer sorpresas y agravarse en el futuro.

No hay variaciones mensuales en la incidencia, que se mantiene entre $6 \mathrm{y}$ $10 \%$ en los distintos meses del año y sin aumento, por tanto, en ninguna estación. Respecto a la distribución por edad, cabe observar que un $20 \%$ corresponde a mayores de 15 años. La letalidad aparece tan alta por la considerable deficiencia de las denuncias. Revela, sin embargo, que la enfermedad es más mortífera en los primeros años, y menor a medida que avanza lą edad (Tabla $\mathrm{N}^{\circ}$ 2).

Tabla $\mathbb{N}^{N} \mathbf{2}$

\section{RJPPUBLICA DE CHILE}

DIFTERIA

Letalidad por edades.

1945-1949

$\begin{array}{cc}\text { Edad } & \text { Letalidad } \% \\ \text { - } 1 \text { año } & 32.1 \\ 1 \text { a } 4 \text { años } & 26.9 \\ 5 \text { a 9 años } & 18.2 \\ 10 \text { a } 14 \text { años } & 7.1 \\ \text { Total edades } & 18.2\end{array}$

\section{2.-Difteria y vacunación mixta en Santiago.}

Como parte del programa que resultó de la ayuda de UNICEF, la Jefatura Provincial de Santiago se propuso, en abril de 1951, vacunar, el primer año, el $40 \%$ de los niños de 3 meses a 6 años y agregar un $10 \%$ cada año, hasta completar el $70 \%$. Calcula que hay 180,000 individuos en este grupo de edad. Emplea la vacuna mixta que prepara el Instituto Bacteriológico y que contiene, en $1 \mathrm{~cm}^{3}, 30$ mil millones de Haemophillus pertussis en fase 1 y $30 \mathrm{~L}$. F. de tøxoide diftérico. La aplica en dos dosis con un mes de intervalo o en tres de $0.5 \mathrm{~cm}^{8}$, con igual ritmo. La inmunidad será reforzada uno y medio o dos años más tarde con una nueva dosis. No obs- 

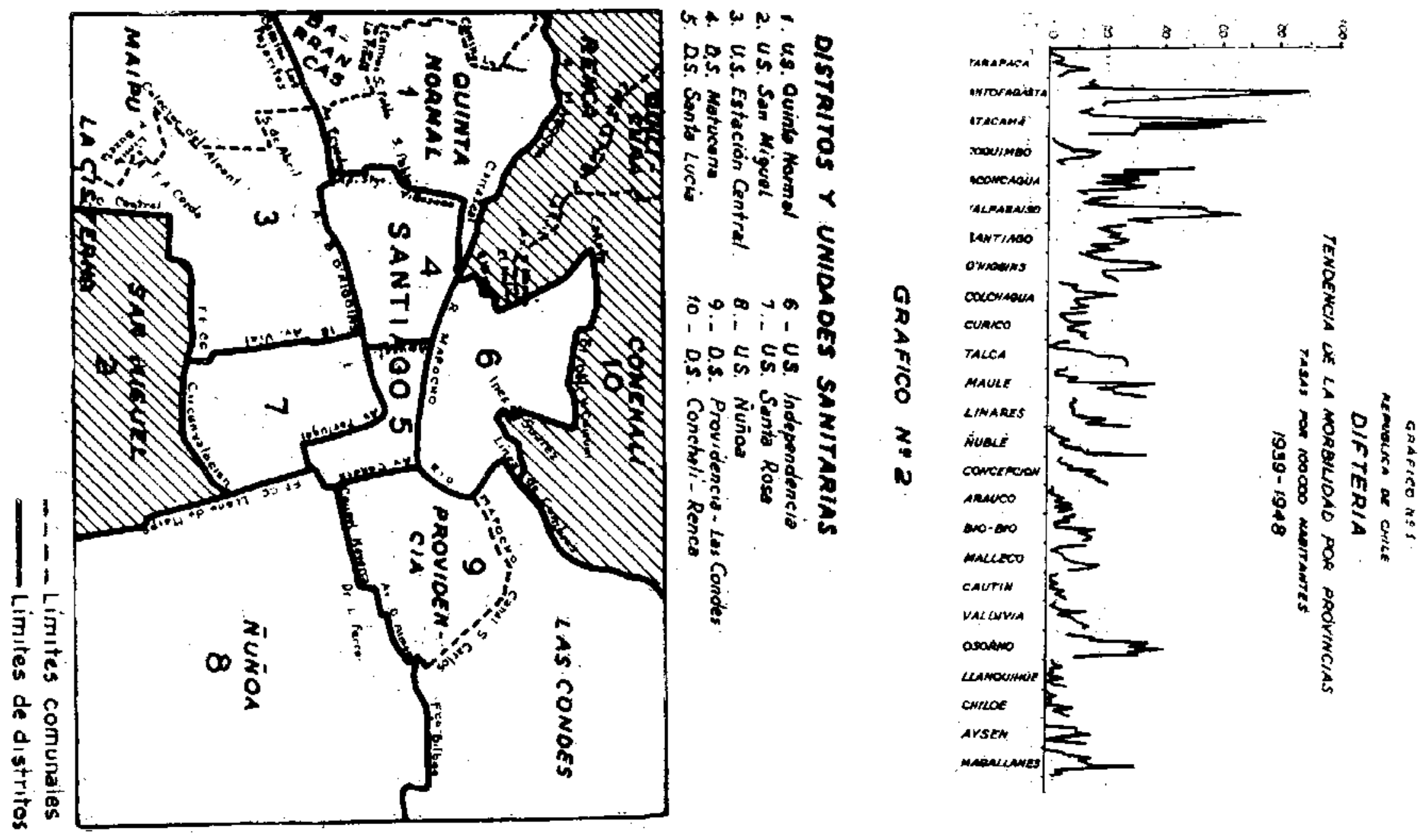
tante haber disminuído considerablemente la intensidad del trabajo en los primeros meses de este año con ocasión del empuje estacional de poliomielítis, se había completado el $86.1 \%$ (Tabla $N^{\circ} 3$ ) al año de su inieiación. y la iniciación del tratamiento. Puede que el pequeño retraso de éste, en los vacunados, se deba a la mayor dificultad de'diagnóstico proveniente de la corta edad de los pacientes y de que no se pieizsa pronto en esta enfermedad cuando

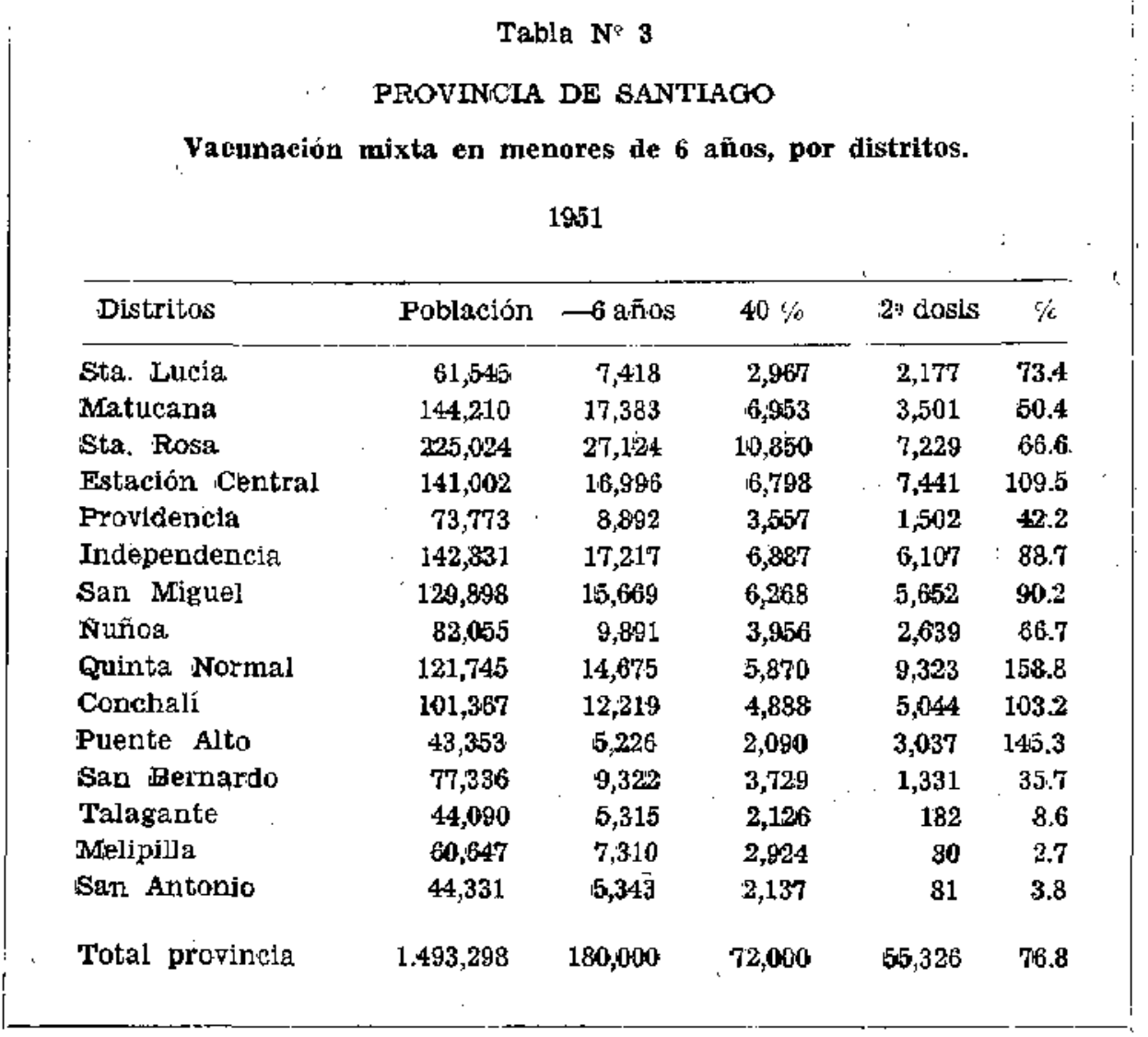

Revisamos 485 encuestas, correspondientes a los casos de difteria que se presentaron en $1951 \mathrm{y}$ en los tres primeros meses del año en curso en 9 distritos sanitarios (Las Condes, Nuñoa, Providencia, Santa Lucía, Santa Rosa, Estación Central, Matucana, Quinta Normal e Independencia), cuya población se estima en 1.089,367 (Gráfico № 2). La dividimos en mayores y menores de 6 años y atribuímos a este grupo 173,919 niños, de los cuales al $1^{\circ}$ de abril se habían vacunado 42,082 . Como revela la Tabla No 4, las denuneias son muy tarđías; pero oportunas la atención médica se supone inmunes a los sujetos. Para estimar la tardanza, hemos recurrido a la mediana y no al promedio, porque la. declaración, la.atención médica y el tratamiento demasiado demorados en unos pocos casos jabrian gravitado fuertemente sobre dicha media aritmética $y$ deformado la realidad.

La denuncia tardía atrasa también las medidas preventivas de aislamiento del enfermo $y$ cuarentena e inmunización de Ios contactos. Así se explica posiblementè la enorme proporción (11.2\%) de Ios casos secundarios (Tabla $N^{o} 5$ ), qué: alcanza su máximo en 


\begin{tabular}{|c|c|c|c|c|c|c|}
\hline \multirow{2}{*}{\multicolumn{7}{|c|}{$\begin{array}{l}\text { Tabla No } 4 \\
\text { DIFTERIA }\end{array}$}} \\
\hline & & & & & & \\
\hline \multicolumn{7}{|c|}{ 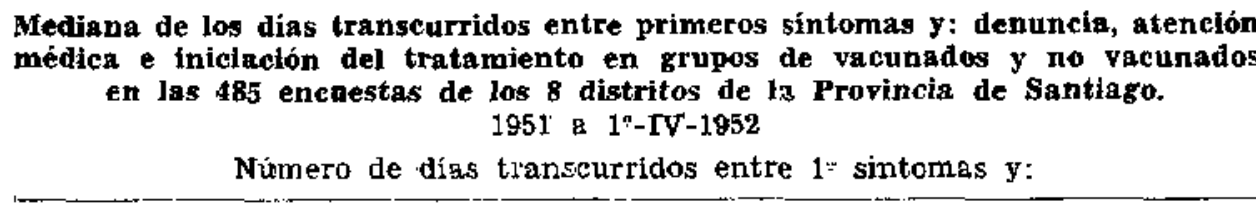 } \\
\hline \multicolumn{4}{|c|}{ Hasta 6 años } & \multicolumn{3}{|c|}{ Mayores de 7 años } \\
\hline . & Denuncia & $\begin{array}{l}\text { Atención } \\
\text { médica }\end{array}$ & $\begin{array}{l}\text { Inicias. } \\
\text { tratam. }\end{array}$ & Denuncia & $\begin{array}{l}\text { Atención } \\
\text { médica }\end{array}$ & $\begin{array}{l}\text { Iniciac. } \\
\text { tratam. }\end{array}$ \\
\hline Vacunados & 5.6 & 1.0 & 2.0 & 5.0 & - & - \\
\hline No vacunados & 5.0 & 1.0 & 1.0 & 5.0 & 1.0 & 1,0 \\
\hline Total & 6.0 & 1.0 & 2.0 & 5.0 & 1.0 & 1.0 \\
\hline
\end{tabular}

Providencia y _Nuñoa $(25.8 \%$ y $13 \%$, Además de tardía, la đeclaración sólo respectivamente), barrios en los cuales ocasionalmente $(7.6 \%)$ proviene de los los pacientes no van al hospital y no médicos tratantes (Tabla $\mathrm{N}^{\circ}$ 6), que deson segregados y donde las condiciones berian constituir la fuente principal, si

\begin{tabular}{|c|c|c|c|c|c|}
\hline \multicolumn{6}{|c|}{$\begin{array}{c}\text { Tabla N: } 5 \\
\text { DLFTERIA } \\
\text { Número de casos secundarios, primarios y porcentaje, por distritos } \\
\text { en las } 485 \text { encuestas de la Provincia de Santiago. } \\
1951 \text { a } 1^{\prime \prime}-\text { IV-1952 }\end{array}$} \\
\hline & $\begin{array}{c}\mathrm{N}^{*} \text { de } \\
\text { encuestas }\end{array}$ & $\begin{array}{l}\mathrm{N}^{\prime \prime} \text { de casos } \\
\text { secundarios }\end{array}$ & $\begin{array}{c}\mathrm{N}^{\text {" de casos }} \\
\text { primarlos }\end{array}$ & $\begin{array}{r}\text { Por } \\
\text { del total }\end{array}$ & $\begin{array}{l}\text { ntaje } \\
\text { de los casos } \\
\text { primarios }\end{array}$ \\
\hline Providencfia & 117 & 24 & 93 & 205 & 25.8 \\
\hline กินñoa & 87 & 10 & 77 & 11.5 & 13.0 \\
\hline Santa Lucia & 32 & 2 & 30 & 6.3 & 6.7 \\
\hline Santa Rosa & 80 & 2 & 78 & 2.5 & 2.6 \\
\hline Inciependencla & 64 & 5 & 59 & 7.8 & 8.5 \\
\hline Quinta Normal & 29 & 2 & 27 & 8.9 & 7.4 \\
\hline Estación Central & 47 & 2 & 45 & 4.3 & 4.4 \\
\hline Ma tucana & 29 & 2 & 27 & 6.9 & 7.4 \\
\hline Total & 485 & 49 & 436 & 10.1 & 11.2 \\
\hline
\end{tabular}

económicas y de cultura no son propi- no única. La son, en cambio, las farmacias para las infecciones subclínicas, de cias a que la Jefatura Provincial indumodo que ha de haber mayor cantidad ce a comunicar, inmediatamente de desde susceptibles. pachadas las recetas de antitoxina difté- 
rica $\mathrm{y}$ de antibióticos, la dirección $\mathrm{y}$ el nombre del afectado. Los comunican, ellas también, tardiamente y suele ocurrir que el pediatra, confiado en esta disposición, no haga la denuncia él mismo. Si bien los casos son visitados por la enfermera o el médico epidemiólogo en las primeras veinticuatro horas, la mayoria de las muestras faríngeas $(71.3 \%)$ son naturalmente negativas, puesto que el paciente leva ya varios días de tratamiento. No está demás recordar que la Jefatura tiene entendimientos con el Instituto Bacteriológico, que le permiten ofrecer examen gratuito de secreción faríngea, como anunció oportunamente al cuerpo médico de la provincia en carta circular.

\section{Tabla $\mathbb{N}^{4} 6$}

\section{DIFTIERIA}

Origen de la denuncia en las 485 encuestas de los 8 distritos de la Provincia de Santiago. 1951 a $1 *-\Gamma-1952$

$\begin{array}{lrr} & \text { Cifra } & \% \\ \text { Hospltales } & 129 & 26.6 \\ \text { Farmacjas } & 184 & 37.9 \\ \text { Particulares } & 34 & 7.0 \\ \text { Médicos particulares } & \mathbf{3 7} & 7.6 \\ \text { Personal Sanitario } & 71 & 14.7 \\ \text { Otros } & \mathbf{2 5} & 5.2 \\ \text { Ignorado } & 5 & 1.0 \\ & & \\ \text { Total } & 485 & 100.00\end{array}$

La cantidad de antitoxina empleada oscila entre 40 y 60 mil unidades; sólo en 6 oportunidades se usó menos de 20,000 y en 16 más de 80,000 . Isa recibieron casi la totalidad de los pacientes $(97.8 \%)$, sea sola $(50.7 \%)$ o combinada con penicilina y de los 8 casos $(2.2 \%)$ a que sólo se coloć́ este antibiótico, 5 tienen comprobación bacteriológica, en tanto que el diagnóstico de los otros 3 merece dudas. Aquí procede recordar también que el Servicio Nacional de Salubridad entrega gratuitamente, según necesidad, antitoxina y penicilina a los indigentes.
Tabla $\mathbf{T}$

\section{DIFTERIA}

Morbilidad y mortalidad, cifras y tasas por 100,000 habitantes. Provincia de Santiago. $1942-1051$

\begin{tabular}{ccccc}
\hline & \multicolumn{2}{c}{ Morbihidad } & \multicolumn{2}{c}{ Mortalidad } \\
Años & iCifra & Tasa & Cifra & Tasa \\
\hline 1942 & 314 & 23.2 & 72 & 6.3 \\
1943 & 274 & 19.6 & 160 & 4.3 \\
1944 & 363 & 25.2 & 59 & 4.1 \\
1945 & 337 & 22.7 & 155 & 3.7 \\
1940 & 192 & 12.6 & 35 & 2.3 \\
1947 & 307 & 19.6 & 55 & 3.5 \\
1948 & 177 & 11.0 & 33 & 2.0 \\
1949 & 200 & 12.1 & 43 & 2.5 \\
1950 & 297 & 17.5 & 37 & 2.3 \\
1951 & 575 & 33.0 & 35 & 2.0
\end{tabular}

En la provincia de Santiago, la morbilidad del último decenio ha sido oscilante (Tabla No 7), como corresponde a esta enfermedad cuando el control no es satisfactorio. Comparando sus tasas en los menores de 6 años (Tabla $N^{0}$ 8) entre vacunados $(45.3$ por 100,000$)$ y no vacunados (127 por 100,000$)$, se puede apreciar una protección que parece reducirlas en proporción de 2,8 a 1 . Para este cálculo y a fín de evitar reparos, tomamos los años-persona de observación y entendemos que, dado el escaso tiempo transcurrido desde la inmunización, las conclusiones tienen carácter preliminar. De todos modos, la diferencia entre estas dos tasas tiene significa$\mathrm{X}$

do estadístico $((--)=4.3)$. A semejanza del país, la mortalidad ha descendido progresivamente en la provincia, gracias de seguro a la generalización del tratamiento adecuado y oportuno. Su tasa es bastante menor (1 a 9.4) en los vacunados y la diferencia tie$\mathrm{X}$ ne significado estadístico $(-)=2.5)$. No ocurre lo mismo con la diferencia de letalidad -que es de 1 a 3.5 -, tal vez por el escaso número de muertos en am- 
Tabla $N^{\circ} 8$

Difteria en vacunados y no vacunados menores de 6 años de la Provincia de Santiago.

1951 a III-1952

\begin{tabular}{|c|c|c|c|c|c|c|c|}
\hline & $\begin{array}{l}\text { Población } \\
\text { al } 31 \text {-III }\end{array}$ & $\begin{array}{l}\text { Poblacion } \\
\text { media (1) }\end{array}$ & Casos & $\begin{array}{l}\text { Tasa } \\
\text { anual }\end{array}$ & Muertos & $\begin{array}{l}\text { Tasa } \\
\text { anual }\end{array}$ & Letalidad \\
\hline Vacunados & 62,018 & 38,870 & 22 & 45.3 & 1 & 2.1 & 4.5 \\
\hline No vacunados & 117,982 & 141,130 & 224 & 127.0 & 35 . & 19.8 & 15.8 \\
\hline Total & 180,000 & 180,000 & 246 & 109.3 & 36 & 16.0 & 14.6 \\
\hline Morbi & $\mathrm{idad}-\frac{\mathrm{x}}{6}$ & 4.3 & & & rtalidad & $-\frac{x}{6} 2.5$ & \\
\hline
\end{tabular}

Relacicn entre morbilidad de vacunados y no vacunados: 1/2.8 Relaclón entre mortalidad de vacunados y no vacunados: 1/9.4 Relación entre letalidad de vacunados y no vacunados: $1 / 3.5$

(1) Población con un año de observación.

Tabla N:9

SANTIAGO Y OONCEPCION

Reacción de Schick.

\begin{tabular}{|c|c|c|c|c|c|c|}
\hline Edad & Total & Positivos & Negativos & $\%$ & $\begin{array}{l}\text { Pseudo } \\
\text { reacciones }\end{array}$ & $\begin{array}{l}\text { Indeter- } \\
\text { minado }\end{array}$ \\
\hline-1 & 65 & 13 & 31 & 47.7 & 18 & 3 \\
\hline 1 & 58 & 22 & 23 & 39.7 & 13 & - \\
\hline 2 & 81 & 28 & 37 & 45.7 & 15 & 1 \\
\hline$\overline{3}$ & 91 & 36 & 28 & 30.8 & 21 & 8 \\
\hline 4 & 105 & 29 & 54 & $\$ 1.4$ & 16 & 6 \\
\hline $\mathbf{5}$ & 105 & 40 & 51 & 48.6 & $g$ & 5 \\
\hline 6 & 151 & 41 & 80 & 53.0 & 28 & 4 \\
\hline 7 & 153 & 61 & 70 & 45.8 & 19 & 3 \\
\hline 8 & 161 & $\cdot 63$ & 72 & 44.7 & 26 & - \\
\hline 9 & 174 & 62 & 75 & 43.1 & 36 & 1 \\
\hline 10 & 186 & 58 & 91 & 48.8 & 31 & 6 \\
\hline 11 & 1.68 & 44 & 87 & 51.2 & 29 & 8 \\
\hline 12 & 207 & 61 & 97 & 46.9 & 45 & 4 \\
\hline 13 & 161 & 47 & 84 & 52.2 & 22 & 8 \\
\hline 14 & 107 & 23 & 58 & $54.2^{\circ}$ & 23 & 3 \\
\hline 15 y 16 & 13 & - & 10 & 76.9 & 1 & 2 \\
\hline 18 y 19 & 15 & 6 & 8 & 58.3 & - & 1 \\
\hline 20 y más & 31 & 23 & 38 & 41.8 & 29 & 1 \\
\hline Total & 2.002 & 657 & 994 & & 370 & 62 \\
\hline
\end{tabular}


bos grupos. El porcentaje total (14.6\%) está dentro de los límites anotados corrientemente.

\section{3. - Schick a distintas edades $y$ anti- toxina circulante en vacunados.}

Originariamente, el Departamento se propuso practicar 3,200 reacciones de Schick en Santiago y Concepción, por mitades. Fueron practicadas aquí por la señorita Ninfa Jiliberto $y$ en la capital por la señorita Silvia Muñoz, ambas enfermeras del Servicio y leídas diariamente por la misma persona durante una semana. Tuvo por objeto tomar, aquí y allá, grupos de 100 individuos entre 3 meses y 1 año y de cada uno de los años de edad hasta 14 más otro de adultos. Eran 16 grupos en total. Se podía esperar asi que se lograra una curva que deseriba la evolución de la inmunidad en las distintas edades. Incidentalmente, se comparó la toxina nacional con una extranjera, preparada por The National Drug Co., de Filadelfia. Si bien las reacciones obtenidas con este producto fueron más nítidas y de lectura más fácil, los resultados guardaban paralelismo tan riguroso que interrumpimos esta comparación. Como revela la Tabla $\mathrm{N}^{9} 9$, no fué posible completar los números deseados por la enorme cantidad de lactantes y preescolares que ya habían recibido vacuna mixta en una y otra ciudad. Se vió, en cambio, la conveniencia de distribuir a los individuos en 19 grupos de edad, La investigación no está terminada y sólo se puede adelantar que los resultados parecen diferir bastante de los aceptados clásicamente. Si bien entre las lecturas que se clasifican como indeterminadas debe haber varias pseudo reacciones $\mathrm{y}$ otras, que, como las pseudo reacciones, están más próximas de las negativas que de las positivas, nuestros resultados revelan indices sostenidamente altos de susceptibilidad en la población.

En 106 muestras de sangre se obtuvieron valores de antitoxina circulante bastante satisfactorios en individuos, to- dos elios, que habían recibido ya dos dosis de vacuna tres meses antes, por lo menos (Tabla $\mathrm{N}^{0} 10$ ). Hay así 78 personas con más de $1 / 50$ de unidad y entre elios, 58 con más de $1 / 10$. Este aspecto de la averiguación está también en proceso.

$$
\text { Tabla } \mathbf{N}^{\ulcorner} \mathbf{1 0}
$$

Resumen de los valores antitóxicos obtenidos en 106 muestras de sangre de niños vacunados con toxoide distérico.

Con más de $1 / 10$ de unidad $x$ cc

Con $1 / 10$ de unidad $x$ cc

Con más de $1 / 50$ y menos de $1 / 10$ de unidad

Con $1 / 50$ de unidad

Con más de $1 / 250 \mathrm{y}$ menos de $1 / 50$ de unidad

Con $1 / 250^{\circ}$ de unidad $x$ ce

Con menos de $1 / 250$ de unidad $x$ cc Total

\section{4.-Estudios bacteriológicos.}

Hace un par de años, el Departamento de Laboratorios y Control del Instituto Bacteriológico y la Cátedra de Microbiología de la Escuela de Salubridad habían observado disminución progresiva de los portadores de bacilos diftéricos aś como aumento del número de Schick positivos en personas adultas. La epidemia de difteria, en un colegio particular de la capital, de que se dió cuenta en la Sociedad Chilena de Salubridad y Medicina Pública (*), indujo a plantearse la conveniencia de estudiar las cepas microbianas, investigación que se ha enriquecido con las aisladas posteriormente en Santiago -en donde ha habido también mayor incidencia- y en Quilpué. Respecto a variedades, nos creemos autorizados para afirmar que estos empujes no se deben a la cepa gravis, como suele suponerse. En muchos países se ha establecido ya que esta variedad no

(*) B. Juricic. L. Vaninj y A. Oviedo: Brate epidémico de difteria en un colegío particular. Rev. Ch. Hig. y Med. Prev. Vol. 13, N $\mathbf{N}^{4}$ : pázs, 27-32. set. 1951 . 
tiene relación con la severidad de las tormas clínicas y en cambio, que tíene importancia para la salubridad la aparición de otras variedades diferentes a las que normalmente existen. De las cepas aisladas por nosotros, que sobrepasan ya las 200, sólo hemos identificado 3 como gravis en medio de Mac Leod y aun ellas no coinciden en todas sus características bioquímicas; la mayoría son mitis.

Debemos anotar, además, que las cepas aisladas en Quilpué tienen gran tendencia a la variación, que no se observa en las santiaguinas. Para algunos autores, este fenómeno revestiría importancia, porque sería la campana de alarma que anuncia posibles epidemias. La determinación de toxicidad de todas
Estos datos preliminares son anticipo de una exposición más detallada. Unidos al porcentaje alto de Schick positivos y a la falta presumible de infecciones subclínicas permite suponer que ia inmunidad básica de nuestra población está bajando, especialmente en los sectores acomodados y que habria razones, por tanto, para continuar los programas de vacunación que podrían restablecerla.

\section{5.-Difteria en Quilpué.}

El doctor Montero había estudiado las tasas de morbilidad del último decenio y determinado que erain considerablemente más altas para la provincia de Valparaíso que para el resto del país.

\begin{tabular}{|c|c|c|c|c|c|c|c|c|}
\hline \multicolumn{9}{|c|}{$\begin{array}{l}\text { Tabla } N^{*} 11 \\
\text { DIFTERIA } \\
\text { QU I L P U E }\end{array}$} \\
\hline \multirow[b]{2}{*}{ Años } & \multicolumn{3}{|c|}{ CASOS } & \multicolumn{3}{|c|}{ DEFUNCIONES } & \multirow{2}{*}{\multicolumn{2}{|c|}{$\begin{array}{c}\text { MORB. MORT. } \\
\text { Total } \\
\text { Tasas x } 100,000 \text { habs }\end{array}$}} \\
\hline & Total & Vac. & No vac. & Total & Vac. & No vac. & & \\
\hline-1 & 1 & - & 1 & - & - & - & 183.2 & - \\
\hline $\operatorname{lin} 4$ & 30 & 6 & 24 & 7 & - & 7 & 1100.1 & $2 \overline{5} 8.5$ \\
\hline $5-9$ & 67 & 17 & 50 & 13 & 2 & 11 & 1890.6 & 368.8 \\
\hline $10-14$ & 20 & 4 & 16 & 2 & 1 & 1 & 1012.8 & 99.0 \\
\hline $15 \mathrm{y}$ más & 9 & - & 9 & 2 & - & 2 & - & - \\
\hline Ign. & 2 & - & 2 & - & 一 & - & - & - \\
\hline Total & 129 & 27 & 102 & 24 & 3 & 21 & 450.3 & 83.8 \\
\hline
\end{tabular}

estas cepas, tanto por los métodos corrientes en animales como in vitro -recientemente introducido éste entre nosotros y cuya posible extensión a la práctica estamos considerando-, revela que en su mayoría son tóxicas. Se ha comprobado también que sus toxinas son neutralizadas en todos los casos, aun en las formas mutantes, por la antitoxina corriente que contiene el suero del Instituto Bacteriológico.
En 1951, la incidencia en Quilpué excedió enormemente de la esperada y lo indujo a practicar la vacunación a que se aludió. Esperó que así disminuyera francamente unos tres meses después de terminada la campaña, en la que creyó haber cubierto porcentajes apreciables de lactantes, preescolares y escolares. Sin embargo, se denunciaron 29 enfer. mos en el primer trimestre de 1952 contra 12 en el mismo período del año an- 
terior y entre ellos había 7 vacunados Santiago y que subia lentamente con el con dos dosis, hacía más de tres meses. aumento de la edad. Se tomaron 451 Todavía más, entre 3 defunciones del muestras faríngeas en personas sanas, primer semestre, 2 corresponden a pre- de las cuales sólo 6 resultaron positivas, suntos inmunizados de ese modo y entre a pesar de que una mayoría importante 42 enfermos, 18 (Tabla $N^{2} 11$ ). La dis- correspondía a contactos. Un dato y tribución de edad en grupos de vacuna- otro sugieren que esta colectividad tamdos y no vacunados es sensiblemente bién había estado libre de infección y igual y la letalidad, extraordinariamen- que su inmunidad colectiva o de grey te alta (Tabla $\mathrm{N}^{\circ} 12$ ), no obstante el era básicamente insuficiente. La búsquemejor conocimiento de los casos que evi- da de bacilos de Loeffler en enfermos dentemente hubo aquí. Emprendimos fué positiva con frecuencia doble que en entonces nuestro programa de colaboración, durante el cual se colocaron 1,500 primeras dosis y 902 segundas de toxoide diftérico. Por razones que no son de este lugar, no empleamos aquí la vacuna mixta. Se completaron así los minimos que indica la Tabla No 12 y que

Santiago, seguramente porque se practicó más oportunamente. Ya se dió cuenta de las determinaciones de antitoxina circulante.

No fué posible tabular los datos que se refieren a enfermos con la precisión que en Santiago. Por tanto, sólo cabe

\begin{tabular}{|c|c|c|c|c|c|}
\hline \multicolumn{6}{|c|}{$\begin{array}{c}\text { Tabla N:12 } \\
\text { DIFTERIA } \\
\text { QUI LP UE }\end{array}$} \\
\hline & Casos & Defunciones & $\begin{array}{l}\text { Morbilidad } \\
\text { Tasa anual } \\
\text { (1) }\end{array}$ & $\begin{array}{c}\text { Mortalidad } \\
\text { Tasa anual } \\
\text { (1) }\end{array}$ & Letalidad \\
\hline Vacunados & 27 & 3 & 910.9 & 101.2 & 11.1 \\
\hline No vacunados & 93 & 19 & 1593.8 & 326.5 & 20.4 \\
\hline Total & 120 & 22 & 1363.8 & 250.6 & 18.3 \\
\hline $\begin{array}{l}\text { (1) Tasa por } \\
\text { gada la d }\end{array}$ & $\begin{array}{l}0,000 \mathrm{~b} \\
\text { rencia }\end{array}$ & $\begin{array}{l}\text { oitantes año } \\
\text { tasas tender }\end{array}$ & $\begin{array}{l}\text { observados. } \\
\text { rá a acentuar }\end{array}$ & observación & nás prolon- \\
\hline
\end{tabular}

cubren la casi totalidad de la población menor de 15 años.

Respecto a las reacciones de Schick, se practicó allí un total de 1,630 en individuos de 4 a 19 años (Tabla No 13). Llamó la atención que alrededor de un $20 \%$ de los individuos que habían recibido ya dos dosis seguían siendo positivos, como también que el porcentaje de negatividad en los no vacunados fué aún más bajo que en Concepción y en decir que los tratamientos no fueron allí tan oportunos y que en 23 casos, por ejemplo, se inició después del quinto día. Nos pareció advertir gran anarquía en las cantidades de antitoxina: así, a un individuo de 85 kilogramos se le colocaron, en total, 20,000 unidades repartidas en 3 dosis y, al otro extremo, 940,000 a un niño de 4 años. La denuncia fué parecidamente tardía y se recibió de médicos particulares en proporción todavía más baja que en la capital. 


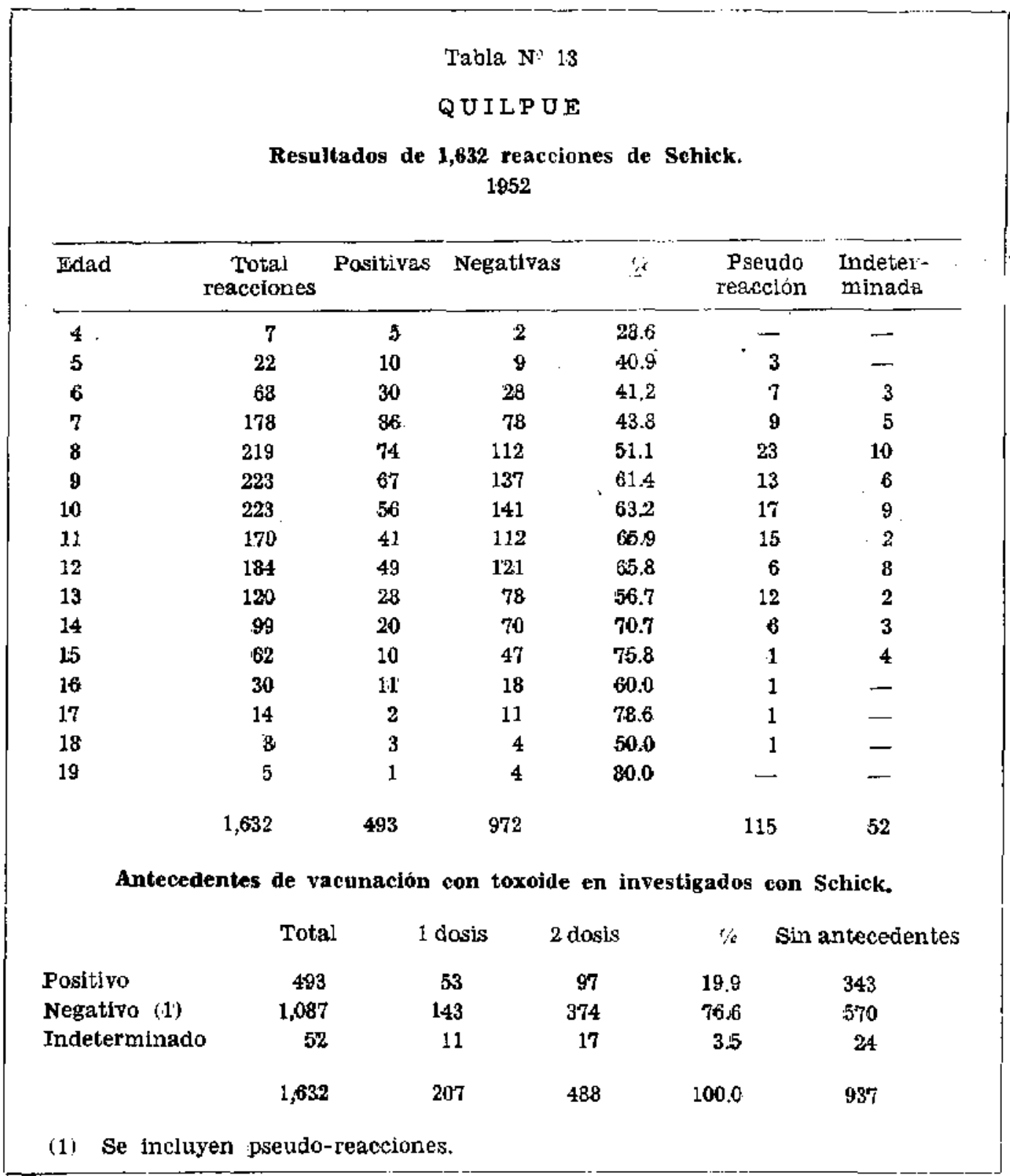

\section{Conclusiones.}

$1^{9}$ Por el momento, las tasas de morbilidad y mortalidad por difteria son bajas en relación con otras causas. Sin embargo, el problema es digno de preocupación, porque la evolución a lo largo de los últimos 45 años sugiere que puedan aumentar.

$2^{\rho}$ Constituye también motivo de preocupación la protección relativamente jnsuficiente que confiere la vacunación con toxoide y que, agregada a la aparente escasez de portadores y al porcentaje elevado de schick positivos, inclina a sospechar que se está perdiendo la inmunidad básica de las colectividades. Esa inmunización podría contribuir a restablecerla.

$3^{9}$ Podrían interpretarse también como motivos de alarma el hallazgo de cepas diferentes a las habituales y que 
han demostrado ser tóxicas. Para la evidenciación de esta cualidad, puede ser útil emplear más ampliamente las pruebas in vitro que el Instituto Bacteriológico está ensayando con éxito.

$4^{\circ}$ La epidemia de Quilpué, que no fué yugulada por el primer programa de vacunación, indujo a emprender un segundo, cuyas características se describen. Las tasas de morbilidad y mortalidad aquí alcanzadas han sido extraordinariamente altas.

$5^{9}$ El control en el expendio de antitoxina y antibióticos ha mejorado la denuncia, que es todavía muy defectuosa y que, más bien, por excepción, se origina en los médicos tratantes. En Santiago, los tratamientos son, en general, oportunos y suficientes.

$6^{\circ}$ La elevada proporción de casos secundarios, especialmente en familias acomodadas, puede ser consecuencia de esos defectos de declaración y del aislamiento, cuarentena e inmunización de contactos insuficientes, que son su consecuencia.

\section{Summary.}

19 For the moment the morbility and mortality for diptheria are low in relation to other causes. Neverless the problem is one that should give food for thought, as the evolution over the last 45 years suggests an increase. $2^{\circ}$ Also a serious problem is the relatively insufficient protection that is given with toxoid vaccination, which added to the apparent lack of carriers and the high percentage of Schick positives, suggests that the population is losing its basic inmunity. Inmunization could contribute to reestablish it.

$3^{\circ}$ The finding of strains different to the usual ones and which have proved to be toxic can also be taken as an alarming manifestation. To prove this fact it might be useful to employ in a greater mannerthe in vitro tests that the Bacteriological Institute is successfully trying out.

$4^{\circ}$ The Quilpue epidemic which was not subjugated by the first vaccination program, started a second one, whose characteristics are described. The morbility and mortality reached, have been extraordinarily high.

$5^{\circ}$ The control in purchasing antitoxin and antibiotics has bettered the reporting which is still very defective and that only as an exception originates from the doctor treating each use. In Santiago, the treatments on the whole are timely and sufficient.

$6^{\circ}$ The high proportion of secondary cases, especially in well todo families, can be the consequence of this lack in reporting and isolation, quarantine and inmunization of insufficient contacts, which are its consequence. 